
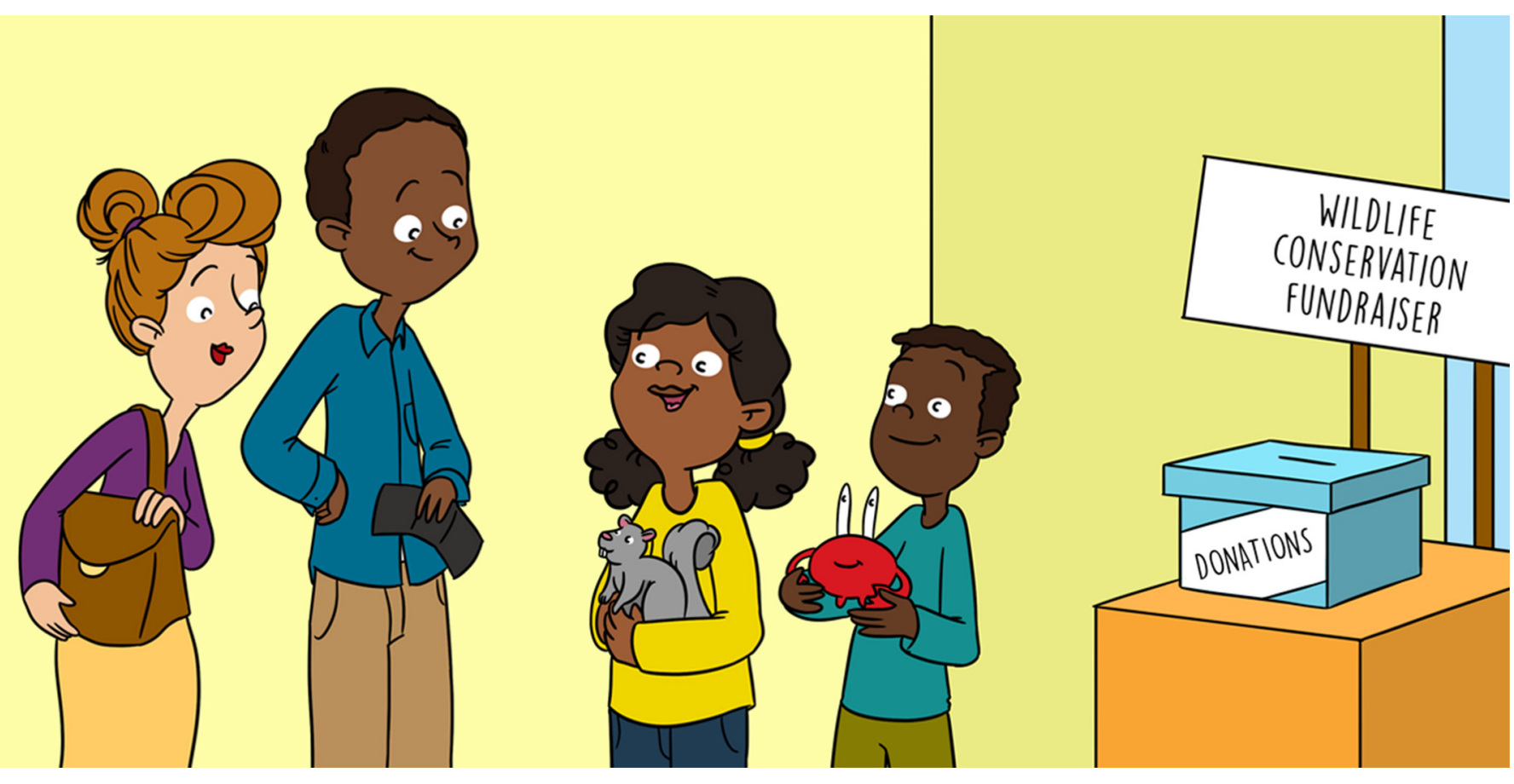

\title{
WHAT WILD ANIMALS DO KIDS CARE ABOUT MOST AND WHY DOES IT MATTER?
}

\section{Nils Peterson ${ }^{1 *}$, Hannah G. Shapiro ${ }^{2}$, Kathryn T. Stevenson ${ }^{3}$, Kristin F. McNair ${ }^{4}$ and R. Brian Langerhans ${ }^{5}$}

\section{${ }^{1}$ Fisheries, Wildlife, and Conservation Biology Program, North Carolina State University, Raleigh, NC, United States \\ ${ }^{2}$ Wildlife and Fisheries Science Program, University of Tennessee, Knoxville, Knoxville, TN, United States \\ ${ }^{3}$ Parks, Recreation, \& Tourism Management, North Carolina State University, Raleigh, NC, United States \\ ${ }^{4}$ Department of Marine Sciences, University of Georgia, Athens, GA, United States}

${ }^{5}$ Department of Biological Sciences and W. M. Keck Center for Behavioral Biology, North Carolina State University, Raleigh, NC, United States

\section{YOUNG REVIEWER:}

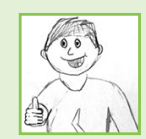

EVERETT

AGE: 12
Wild animals are disappearing from the earth, or going extinct, far faster than normal. People working to save wildlife from extinction are called conservation biologists, and sometimes they must pick which wildlife species to save. Many conservation biologists are trying to protect wildlife so kids can live in a world where those animals still exist. So, knowing which animals kids care about is important. Our work revealed that kids care most about beautiful animals like flamingos and wolves, but kids from different places care about different kinds of animals. Kids from areas further from the ocean cared most about animals that were naturally in that environment, like black bears and white-tailed deer. Kids from a small island cared more about animals in the ocean and animals that were originally turned loose by people, like wild pigs and cats. Our work 


\section{shows how conservation biologists can work to help the animals that kids value.}

\section{WHY DOES IT MATTER WHICH ANIMALS KIDS CARE ABOUT?}

Conservation biologists are scientists who work to save wildlife from extinction. They often need to choose which kinds of wild animals, or wildlife, to protect. This choice must happen because there is not enough money, time, or conservation biologists to save all the different types of wildlife that are going extinct. Species are going extinct up to 1,000 times faster than is natural. In the past, major extinction events were caused by natural disasters, like giant asteroids hitting the earth, but now extinction is caused by things people do, mainly damaging natural landscapes when building new houses and farms, causing rapid climate change, directly killing wildlife for food or to sell, and releasing invasive species [1]. Invasive species are species that did not naturally live in an area but spread rapidly and cause damage after people release them.

As conservation biologists cannot save every species, they must choose reasons to focus on saving a few species. Common reasons for using limited resources to save a species include whether the number of animals of that species is declining, whether the total number is low, and whether that species only lives in one small place, and could easily become extinct. Recently, conservation biologists have decided to also consider how much species matter to people. This is a good idea, because efforts to save species only succeed when people help [2]. People must choose to pay for protecting places where wildlife live and they must also be willing to stop doing the things that hurt wildlife, like letting pet cats live outside where they eat birds and other small animals, or building houses in places where wild animals need to live.

Scientists found that adults tend to care most about beautiful animals, like colorful birds, and exciting animals, like lions and tigers [3]. Similarly, adults like birds and mammals more than they like snakes, lizards, and insects. Recently, scientists have started studying which species kids care about most. Even though kids do not vote, pay for wildlife conservation, or make decisions about where to build houses, their opinions matter for multiple reasons. First, one of the main reasons people work to stop extinction is to ensure that many species are still around for today's kids, and future kids, to enjoy. Second, kids are great at helping their parents decide to do things that are good for nature, including recycling, stopping littering, working to slow down climate change, and saving wildlife from extinction [4]. Parents tend to trust their kids' opinions. So, the types of wildlife kids care about are important, because conservation biologists are working to save 
species for kids, and kids can help their parents to help conservation biologists succeed!

Kids' wildlife preferences are similar to adults' preferences in some ways. Both kids and adults care about mammals and birds more than reptiles and insects, and they both like fascinating megafauna. Megafauna are large, wild animals, typically larger than humans, such as bears, whales, crocodiles, ostriches, great white sharks, and giant squids. But kids' preferences also differ from those of adults in some ways. Kids care more about turtles, snails, and butterflies than adults do [5]. Not all kids are the same though. For instance, some boys like scary animals, like spiders, more than girls do, and some girls like cute animals, like hedgehogs, more than boys do [5]. Both kids and conservation biologists often care most about species that are important in nature [6]. Prior to this study, we did not know anything about how living in different places influenced which species kids cared about. This is important because different places have different species, and often also have different threats to their species. For example, invasive species are the main cause of extinction on islands. Feral cats, feral pigs, and snakes have caused many extinctions in these locations. Feral refers to animals living in the wild after escaping from a home, farm, or other form of captivity.

The goal of our research was to compare species preferences among children in North Carolina (USA) and children in Andros Island (The Bahamas). North Carolina and Andros Island were interesting study sites, because the causes of extinction there match what occurs on continents (big land areas) and island locations everywhere. We tested the hypothesis that children on Andros Island would prefer invasive species more than children in North Carolina. This hypothesis was based on previous science suggesting that adults living on islands opposed removing invasive species [7]. We also explored whether boys preferred animals that were stereotypically scary or gross more than girls did, since that relationship was found in previous research [5].

\section{MEASURING KIDS' PREFERENCES FOR DIFFERENT ANIMALS}

To test our hypothesis, we asked the opinions of kids from North Carolina, USA and Andros Island, The Bahamas. We worked with 433 kids in North Carolina who were between 8 and 11 years old. On Andros Island, we worked with 197 kids who were between 5 and 12 years old. In both cases, we traveled to the students' classrooms and asked them the questions in person. The most important question we asked all the kids was: What are your five favorite kinds of wild animals that live in North Carolina (or in The Bahamas)? We included a species in the study if at least $10 \%$ of the kids in either place mentioned it as among their favorites. Species that were mentioned 
Figure 1

Comparison of kids in North Carolina (NC) and Andros Island (Andros) in terms of which types of wild animals were their favorites. You can see that where the kids were from affected which animals they preferred.

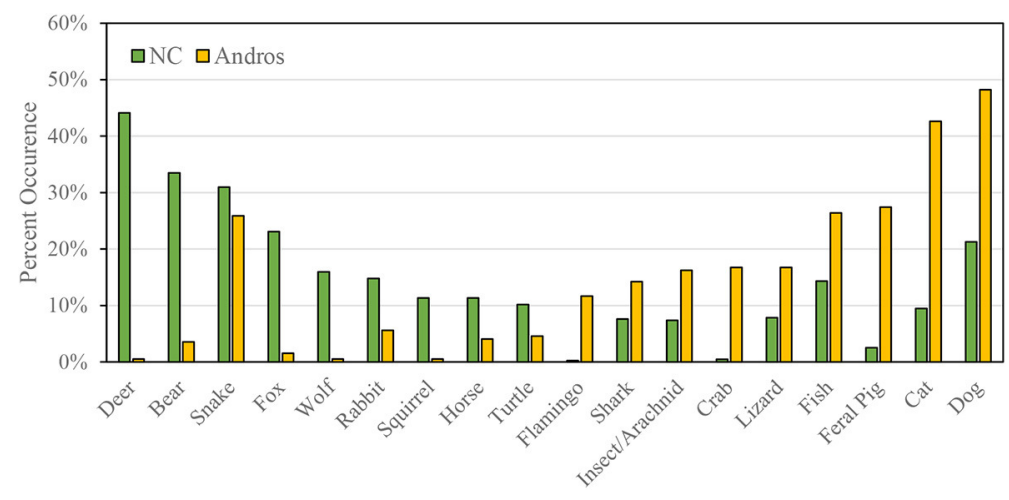

Figure 1

less often were grouped together with other similar species into a bigger category, like birds, instead of the species category, like robin. We calculated the percent of times kids mentioned various animals, including invertebrates (animals without a backbone like insects and squid), species that live in the water, and invasive species. To evaluate whether location or being a girl or boy mattered, we used mathematical techniques known as statistics to analyse our data [8]. We used these mathematical methods to see if two things about kids, their gender and where they lived, predicted which groups of species they cared about most.

\section{WHICH ANIMALS DID KIDS CARE ABOUT MOST?}

We discovered that whether kids were from an island or continent was the most important factor for predicting the groups of species they cared about most. Being from an island or a continent predicted $26 \%$ of the species kids listed. Being a girl or boy also mattered, but was much less important and only predicted $3 \%$ of the species kids cared about. As you might guess, kids cared a lot about big, exciting animals, including sharks, birds, and mammals (Figure 1). Differences between the island and continental kids were huge. Kids from Andros Island cared about fish, crabs, insects, flamingos, cats, dogs, and pigs more than kids from North Carolina did. On the other hand, kids from North Carolina cared more about deer, bears, foxes, wolves, and rabbits than kids from Andros Island did. Some of these differences make sense, because fish and crabs are more important on an island than on a continent, and Andros has wild flamingos, but North Carolina does not.

Some of the biggest differences seen between the kids in the two locations were for invasive species that were common in both places, including feral cats, dogs, and pigs. Kids mentioned invertebrates and aquatic species more often if they were from Andros (Figures 1, 2). Most (65\%) children surveyed on Andros Island mentioned at least one of the feral invasive dog, cat, or pig species. Boys in 
Figure 2

Percentages of kids in North Carolina (NC) and Andros Island (Andros) that chose invertebrates, aquatic species, and invasive species as among their favorites. You can see that kids from Andros chose all three types of species more than kids in NC did.

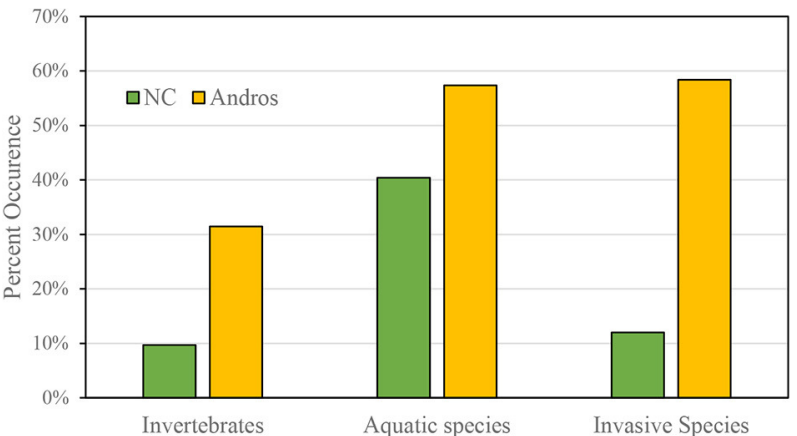

Figure 2

both regions had greater preferences for lizards and fish, and girls had stronger preferences for various mammals, including rabbits and horses. Although these differences between boys and girls suggest that gender matters, the results did not fit with previous research suggesting boys liked insects, spiders, snakes, and sharks more than girls do [5].

\section{HOW CAN THESE RESULTS BE EXPLAINED?}

Perhaps kids from Andros preferred invasive species because feral cats, dogs, and pigs are more common, more visible, and more important there than in North Carolina. Scientists studying these issues on other islands discovered that invasive species like feral pigs can be important for providing local people with food and recreation [7]. Kids on Andros Island may have liked feral pigs for similar reasons, since hunting them for recreation and food was common on the island. Feral dogs and cats are often viewed positively because they remind people of beloved pets. In North Carolina, kids loved wolves, a naturally occurring and wild animal that is closely related in both appearance and evolutionarily to dogs. The only wild animals similar to pets on Andros were feral invasive species. Crabs and fish seem to be more important in the lives of people living on islands than in the lives of people living on a large continental land mass, and that may explain why kids in Andros cared more about those species. We are not sure why girls liked rabbits and horses more than boys. Boys might like fish more than girls because boys are more likely to go fishing than girls are. This is true in many locations, including Andros Island and North Carolina.

\section{HOW CAN THESE RESULTS BE USED FOR PROTECTING SPECIES?}

These discoveries suggest that conservation biologists on islands face challenges from both nature and the people living there. Wildlife on islands is most easily driven to extinction by invasive species, and the 
most effective way to address that issue is by removing invasive species from islands. Removing an animal species is difficult even when local people support it, but the discoveries presented here indicate that kids on islands really care about invasive species and might not want them removed. Conservation biologists need to explain the negative effects of invasive species and introduce kids who live on islands to their own unique, native species. Native species are species living in the place where they developed. Once kids learn about local native species they typically care more about them [6]. We often get advice to pay attention to the little things, and that is especially important for kids on islands, where the exciting native wildlife species are often little things like insects and lizards. People only work to protect things they care about, and people will only care about native species after they know the species exist. Educating people about local wildlife can be a first step toward protecting the natural landscapes wildlife needs to survive. Kids can play an important role in this process by learning about biodiversity, and sharing what they know with their parents [4].

\section{ORIGINAL SOURCE ARTICLE}

Shapiro, H. G., Peterson, M. N., Stevenson, K. T., Frew, K. N., and Langerhans, R. B. 2017. Wildlife species preferences differ among children in continental and island locations. Environ. Conserv. 44:389-96. doi: 10.1017/S0376892917000133

\section{REFERENCES}

1. Brook, B. W., Sodhi, N. S., and Bradshaw, C. J. 2008. Synergies among extinction drivers under global change. Trends Ecol. Evol. 23:453-60. doi: 10.1016/j.tree.2 008.03.011

2. Kaltenborn, B. P., Bjerke, T., Nyahongo, J. W., and Williams, D. R. 2006. Animal preferences and acceptability of wildlife management actions around Serengeti National Park, Tanzania. Biodivers. Conserv. 15:4633-49. doi: 10.1007/s10531005-6196-9

3. Prokop, P., and Fančovičová, J. 2013. Does colour matter? The influence of animal warning coloration on human emotions and willingness to protect them. Anim. Conserv. 16:458-66. doi: 10.1111/acv.12014

4. Peterson, M. N., Stevenson, K. T., and Lawson, D. F. 2019. Reviewing how intergenerational learning can help conservation biology face its greatest challenge. Biol. Conserv. 235:290-4. doi: 10.1016/j.biocon.2019.05.013

5. Borgi, M., and Cirulli, F. 2015. Attitudes toward animals among kindergarten children: species preferences. Anthrozoös 28:45-59. doi: 10.2752/089279315 X14129350721939

6. Shapiro, H. G., Erickson, K. A., Peterson, M. N., Frew, K. N., Stevenson, K. T., and Langerhans, R. B. 2016. Which species to conserve: evaluating children's species-based conservation priorities. Biodivers. Conserv. 25:539-53. doi: 10.1007/s10531-016-1067-0 
7. Ogden, J., and Gilbert, J. 2011. "Running the gauntlet: advocating rat and feral cat eradication on an inhabited island-Great Barrier Island, New Zealand," in Island Invasives: Eradication and Management, eds C. R. Veitch, M. N. Clout, and D. R. Towns (Gland: IUCN). p. 467-71.

8. Chapman, M., and Underwood, A. 1999. Ecological patterns in multivariate assemblages: information and interpretation of negative values in ANOSIM tests. Mar. Ecol. Prog. Ser. 180:257-65.

SUBMITTED: 23 October 2019; ACCEPTED: 28 January 2020;

PUBLISHED ONLINE: 27 February 2020.

EDITED BY: Michele A. Johnson, Trinity University, United States

CITATION: Peterson MN, Shapiro HG, Stevenson KT, McNair KF and Langerhans RB (2020) What Wild Animals Do Kids Care About Most and Why Does It Matter? Front. Young Minds 8:14. doi: 10.3389/frym.2020.00014

CONFLICT OF INTEREST: The authors declare that the research was conducted in the absence of any commercial or financial relationships that could be construed as a potential conflict of interest.

COPYRIGHT @ 2020 Peterson, Shapiro, Stevenson, McNair and Langerhans. This is an open-access article distributed under the terms of the Creative Commons Attribution License (CC BY). The use, distribution or reproduction in other forums is permitted, provided the original author(s) and the copyright owner(s) are credited and that the original publication in this journal is cited, in accordance with accepted academic practice. No use, distribution or reproduction is permitted which does not comply with these terms.

\section{YOUNG REVIEWER}
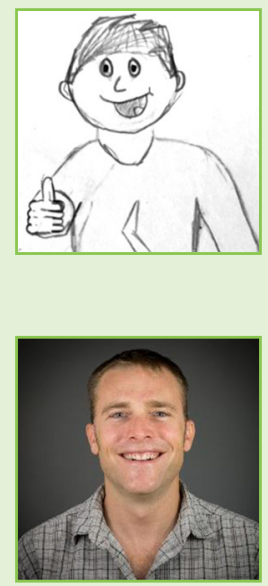

\section{EVERETT, AGE: 12}

I am an energetic open minded 12 years old. I have always liked science to some extent, but I find it very interesting this year in particular.

\section{AUTHORS}

\section{NILS PETERSON}

M. Nils Peterson is a Professor of Fisheries, Wildlife, and Conservation Biology at North Carolina State University. His research focuses on environmental behavior, using environmental education, environmental conflict, and environmental policy making as natural experiments to test hypotheses. Nils received his B.S. and M.S. degrees from Texas A\&M University, and his Ph.D. from Michigan State University. Additional information about his research, teaching, and service activities is on his web page (https://faculty.cnr.ncsu.edu/nilspeterson/). *nils_peterson@ ncsu.edu 

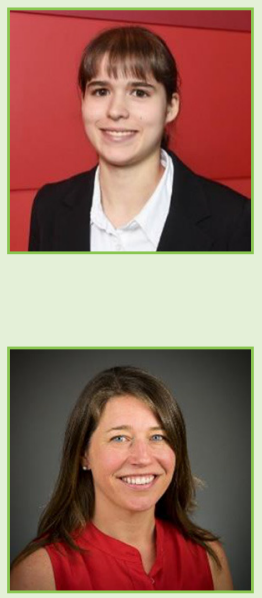

HANNAH G. SHAPIRO

Hannah G. Shapiro is a master's student at the University of Tennessee in the Wildlife and Fisheries Science program. Her master's project focuses on visitor perceptions of bats and cave management actions in U.S. national parks, with the goal of improving conservation and recreation in these parks. Hannah received her B.S. degree from North Carolina State University.

\section{KATHRYN T. STEVENSON}

Kathryn T. Stevenson is an assistant professor in the Department of Parks, Recreation \& Tourism Management at NC State. She researches and teaches about children and nature, including what benefits kids get from being outside, and how kids can inspire adults to work together to address environmental challenges. You can learn more about Dr. Stevenson's work by visiting go.ncsu.edu/Stevenson.

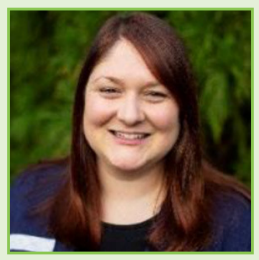

\section{KRISTIN F. MCNAIR}

Kristin Frew McNair is an administrative specialist in the Department of Marine Sciences at the University of Georgia. Her position supports research on marsh ecology and educational opportunities for college students. Kristin received her B.S. degree in Wildlife and Fisheries Science from Mississippi State University and her M.S. degree in Fisheries, Wildlife, and Conservation Biology from North Carolina State University. She is also currently pursuing a Master of Public Administration at the University of Georgia.

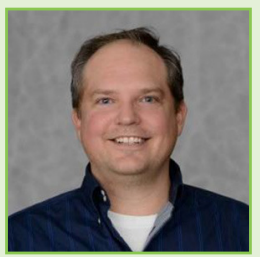

\section{RANDALL BRIAN LANGERHANS}

Brian Langerhans is an Associate Professor of Biological Sciences at North Carolina State University. His research focuses on understanding the predictability of biological evolution, the causes of the formation of new species, and the role of human activities in driving rapid changes in the traits of native organisms. Brian received B.S. and M.S. degrees from Texas A\&M University, a M.A. degree from Washington University in St. Louis, and a Ph.D. from Harvard University. More information about his research and teaching is on his web page (http://gambusia.zo.ncsu.edu/). 